\title{
Hexadecylphosphocholine: a new and selective antitumor drug
}

\author{
H. Eibl* and C. Unger $†$ \\ * Max-Planck-Institute for Biophysical Chemistry and $\uparrow$ Division of Hematology/Oncology, \\ Department of Internal Medicine, University Hospital Göttingen, D-3400 Göttingen, Germany
}

\section{Introduction}

In the 1960s, the first evidence was obtained at the Max-Planck-Institute in Freiburg that lysolecithins, as a consequence of their high affinity to the cell membrane, not only cause changes in permeability $(7,16)$, but are also catalysts in more complex cellular events. Synthetic (ether)-lysolecithins have been shown to be capable of influencing the mammalian body's own immune system (13). The effects obtained were structurally dependent. (Ether)-lysolecithins with long-chain alkyl residues $\left(\mathrm{C}_{16}\right.$ and longer) led to immunostimulation. Those with short-chain alkyl chains $\left(\mathrm{C}_{15}\right.$ and shorter), led to immunosuppression. The lack of (ether)-cleaving enzymes in carcinomas (17) was particularly interesting because of the possible use of (ether)-lysolecithins in the therapy of malignant tumors. This finding led to the hypothesis that (ether)-lysolecithins could be metabolized in normal cells, but not in malignant tissues. Based on differences in the enzyme content of neoplastic cells and normal cells, selective activity of the (ether)-lysolecithins towards tumor cells might be expected. In 1982, we started our investigations on the antitumor efficacy of phospholipids and analogs.

\section{From (ether)-lysolecithins to alkylphosphocholines}

Numerous studies have shown that 1-O-octadecyl-2-O-methyl-rac-glycero-3-phosphocholine inhibits the growth of methyl nitrosourea induced breast carcinomas in the rat. Surprisingly, the effect of these substances was not very selective (3). Therefore, the importance of the (ether)-cleaving enzyme as a selective detoxifying agent in normal cells was put in doubt. It was the aim of the present investigations to determine through systematic analysis of the metabolism of structurally modified (ether)-lysolecithins which structures might be selective. The study was expected to provide information on the minimal structural requirements for antitumor efficacy and, if possible, on which of these elements were responsible for selectivity. Our investigations were the first to discover a correlation between chemical structure, antitumor efficacy and selectivity. Of major importance for these investigations was the development of simple methods for the preparation of lysolecithins and analogs $(6,7,8,21)$. 

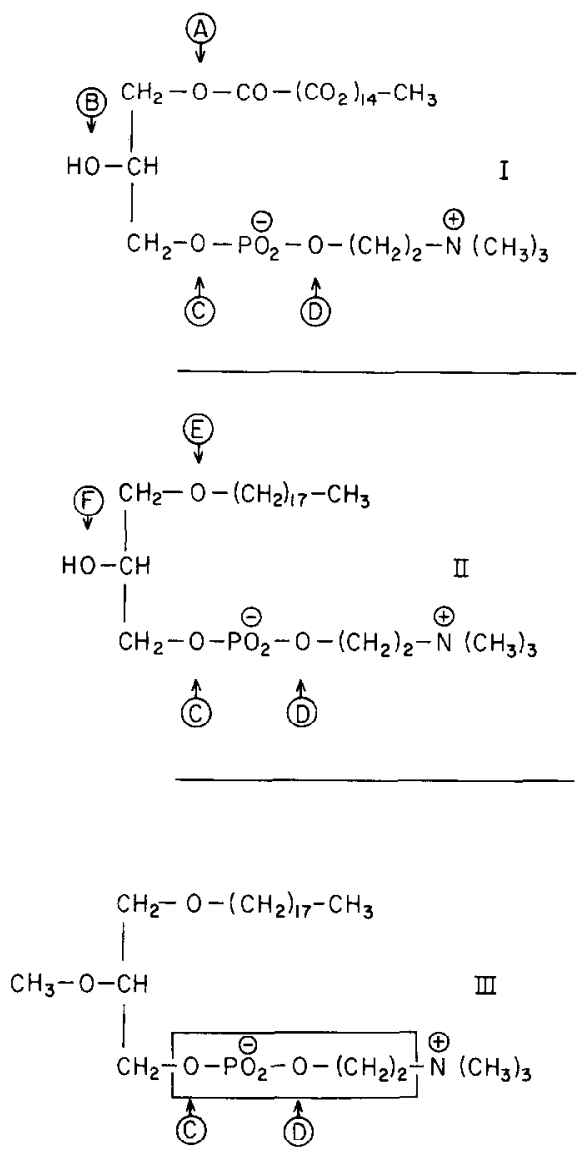

Figure 1. Chemical structure of (ester)- and (ether)-lysolecithins. The arrows indicate attack sites for phospholipid metabolizing enzymes: (a), phospholipase $A_{1}$; (b), acyltransferase; (c), phospholipase $C$; (d), phospholipase D; (e), $\mathrm{O}$-alkylglycerol monooxygenase; (f), transesterasc. The squarcd-in area charactcrizes structural clements which are essential for antineoplastic activity.

Figure 1 shows a series of lysolecithins whose structures are purposefully varied. For instance, compounds I and II are naturally occurring intermediates and non-toxic. With compound III, 1-O-octadecyl-2-O-methyl-rac-glycero-3-phosphocholine, we achieved compounds which are almost metabolically stable. This stability generates anti-neoplastic activity in vivo (3).

The antitumor efficacy of 1-O-octadecyl-2-O-methyl-rac-glycero-3-phosphocholine (III) compared to substances I and II is not explained solely on the basis of its physical properties. For instance, hemolytic activity and critical micelle concentration of these compounds with values of about $10^{-5} \mathrm{M}$ differ strongly. It is more likely that substrate properties towards phospholipid metabolizing enzymes are responsible for the antitumor activity. It follows from Figure 2 that 1-palmitoyl-sn-3-glycero-phosphocholine (I) in microsomes derived from rat livers can, in the presence of oleoyl-CoA, be rapidly transformed into 1-palmitoyl-2-oleoyl-sn-glycero-3-phosphocholine (I) and thereby detoxified. The enzymes responsible for this are the acyltransferases (5). Surprisingly, and contrary to the current views, acyltransferases cannot acylate and, therefore, cannot detoxify the 


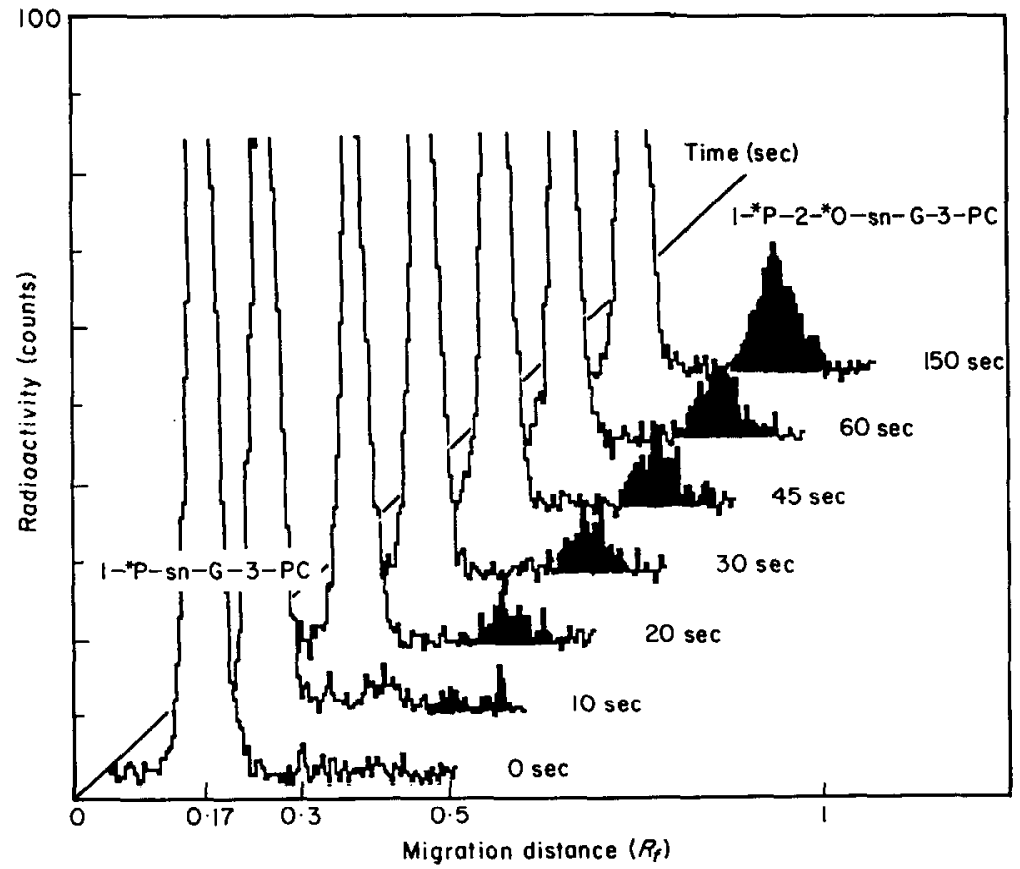

Figure 2. Microsomal protcin from rat livers $(0.15 \mathrm{mg})$ was incubatcd with $170 \mathrm{nmol}\left({ }^{3} \mathrm{H}\right)$-labellcd 1-palmitoylsn-glycero-3-glycero-phosphocholine $(R f$-value 0.17$)$ and $50 \mathrm{nmol}\left({ }^{14} \mathrm{C}\right)$-labelled oleoyl-CoA at $37^{\circ} \mathrm{C}$ in $1 \mathrm{ml}$ buffer at $\mathrm{pH} 7.4$. According to the times given, the reaction was stopped by the addition of formic acid. After freeze-drying, the residue was extracted with chloroform, applied to silica gel plates and developed using the solvent system chloroform/methanol/glacial acetic acid/water 100:60:20:5 (per vol.). Increasing amounts of radioactive product formed in a time-dependent manner with the $R f$-value 0.40 , 1-palmitoyl-2-oleoyl-sn-glycero3-phosphocholine.

corresponding (ether)-lysolecithins, e.g. 1-O-octadecyl-sn-glycero-3-phosphocholine (1I). As shown in Figure 3, under the optimal acylating conditions worked out for 1-palmitoyl$s n$-3-glycero-phosphocholine (I), no product is formed with 1-O-octadecyl-sn-glycero-3phosphocholine in the presence of oleoyl-CoA (15). (Ether)-lysolecithins are not substrates for acyl-CoA dependent acyltransferases. However, detoxification is still possible by means of other enzymes. For instance (ether)-lysolecithins (II) can be cleaved by $O$-alkylglycerol monooxygenases or possibly via other acylating enzyme systems of the cell.

We have, however, found enzymes which can detoxify 1-O-octadecyl-sn-glycero-3phosphocholine in the absence of acyl-CoA. The enzymes are transesterases which transfer fatty acids from inositolphosphatides into the 2-position of (ether)-lysolecithins (15). These results are summarized in the deacylation-reacylation cycles for 1,2-diacyl-sn-glycero-3phosphocholine and 1-O-alkyl-2-acyl-alkyl-sn-glycero-3-phosphocholine (Figure 4). Both groups of substances are turned into the corresponding single-chain compounds by phospholipase $\mathrm{A}_{2}$. Reacylation, however, takes place via various enzymes and with different cosubstrates.

In comparison to the (ester)- and (ether)-lysolecithins with free hydroxyl groups in the $s n$-2-glycerol position which can be acylated, 1-O-octadecyl-2-O-methyl-glycero-3phosphocholine (III) is certainly no substrate for acylating enzymes. The hydroxyl group in the $s n-2$ position is blocked by a methyl group. Remarkably, this compound is not a 


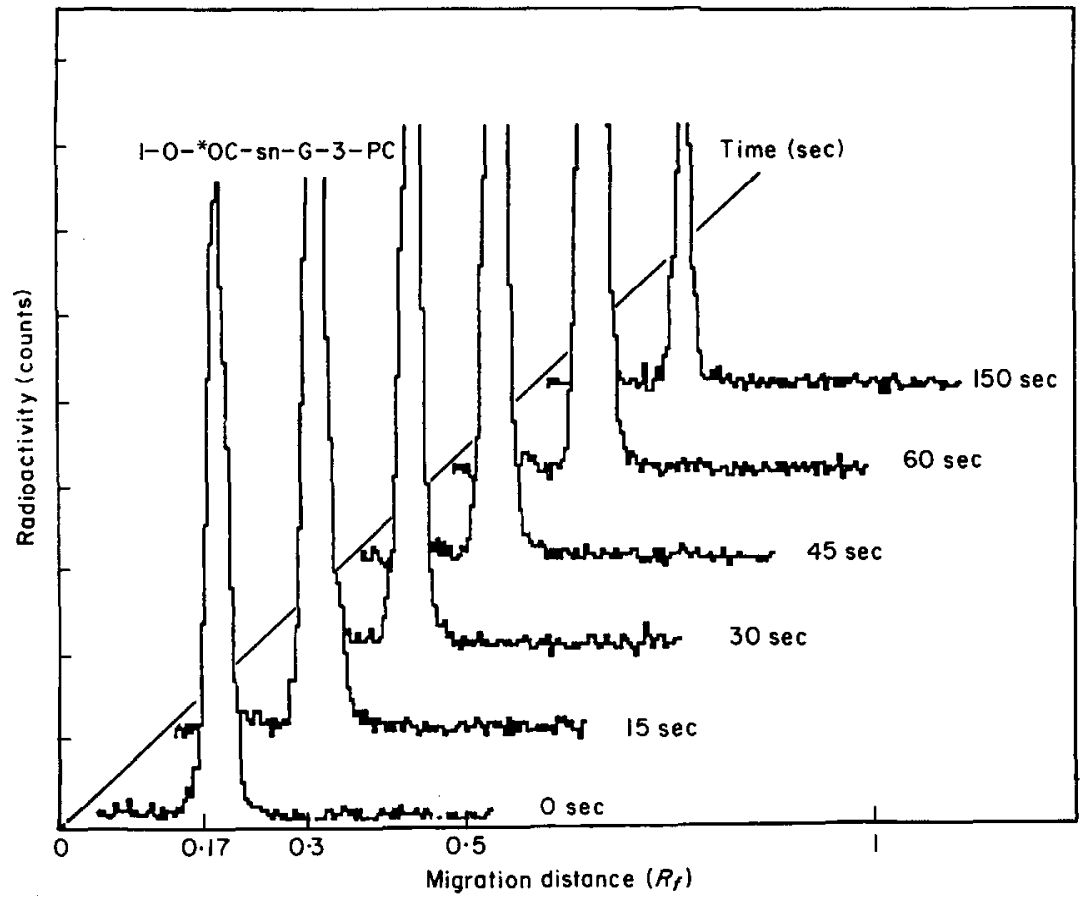

Figure 3. The conditions for incubation and the type of processing are as stated in Figure 2. However, $\left({ }^{3} \mathrm{H}\right)$ labelled 1-O-octadecyl-sn-glycero-3-phosphocholine ( $R f$-value 0.17$)$ was used instead of the (ester)-lysolecithin. Product formation was no longer obscrved. $\Lambda$ cyl-Co $\Lambda$ dependent acyltransferases cannot acylate (cther)lysolecithins.

substrate for $O$-alkylglycerol monooxygenases. We were able to prove this with newly developed methods $(10,11,20)$. The difference in the enzyme contents of tumor compared to normal cells cannot lead to a selective destruction of tumor tissue because 1 - $O$-octadecyl2-O-methyl-sn-glycero-3-phosphocholine and the enantiomer 3-O-octadecyl-2-O-methylsn-glycero-1-phosphocholine are lacking the necessary substrate properties for $O$-alkylglycerol monooxygenases. The selective activity that has been discussed in connection with differences in the enzyme content of tumor and normal cells for $O$-alkylglycerol monooxygenases $(2,13)$ has not received experimental confirmation $(18)$.

From our experimental findings on the substrate properties of these substances, on their metabolism in cell cultures and in various organs, including rat tumors, it is possiblc to say that it is these missing substrate properties for alkylglycerol monooxygenases that are the critical requirements for tumor growth inhibition produced by these compounds. Only 1-O-octadecyl-2- $O$-methyl-rac-glycero-3-phosphocholine has antineoplastic properties and, at the same time, is a marginal substrate for phospholipase $\mathrm{C}$ and $\mathrm{D}$. In addition, a transfer of phosphocholine to diacylglycerol is obscrved (Figure 5). The analogous compound with an enlarged distance between phosphate and trimethylammonia (IV), as shown in Figure 6, has no substrate properties for phospholipid metabolizing enzymes and is inactive. Substance V, 1-O-octadecyl-propandiol-3-phosphocholine is a substrate for $O$-alkylglycerol monooxygenase and can therefore be detoxified. Our prediction from these observations is that the minimal structural elements for antineoplastic activity are given by an alkanol of chain length $\mathrm{C}_{16}$ to $\mathrm{C}_{18}$ attached to phosphocholine. 


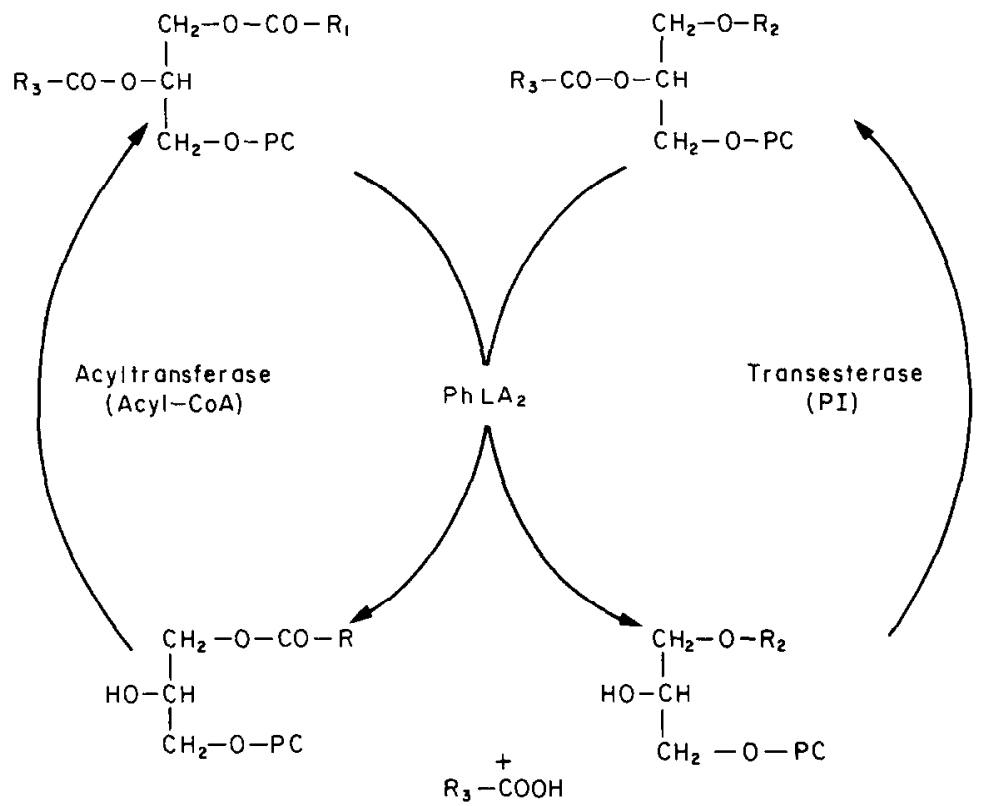

Figure 4. The different metabolism of 1,2-(diacyl)-lecithins and of 1-O-(alkyl)-lecithins (deacylation-reacylation cycles). PLA $A_{2}$, phospholipase $A_{2}$; PC, phosphocholine; PI, phosphatidylinositol; $R_{1}, R_{2}$ and $R_{3}$, alkyl residues. Hydrolysis with PLA $\mathrm{A}_{2}$ occurs independently of an ester or ether function in the $s n-1$ glycerol position. Reacylation of (ester)-lysolecithins is catalyzed by acyltransferases, reacylation of (ether)-lysolecithins by transesterases.

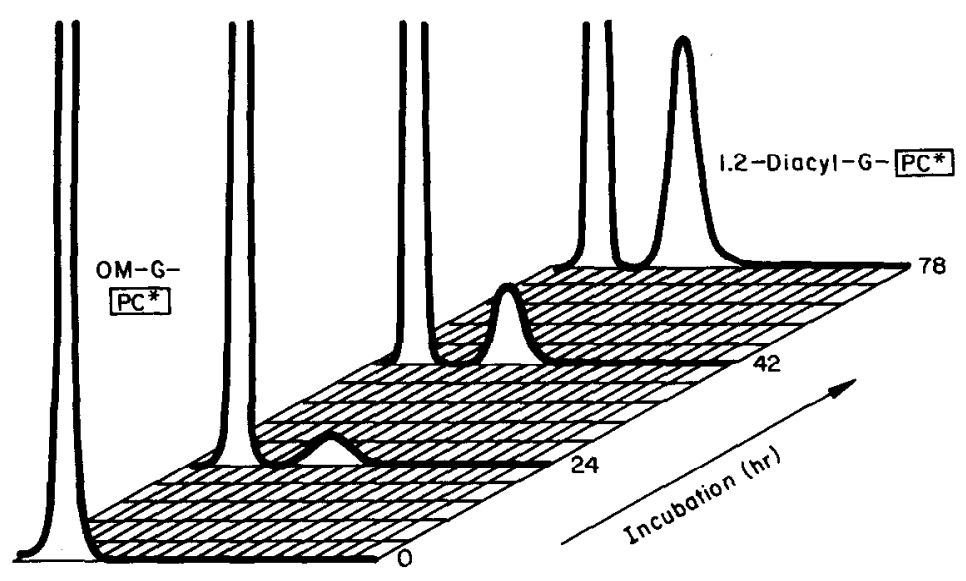

Figure 5. Metabolism of 1-O-octadecyl-2-O-methyl-rac-glycero-3-phosphocholine in Raji cell cultures. The cells wcrc incubated with labcllcd $1-O$-octadccyl-2- $O$-mcthyl-rac-glyccro-3-phospho- $\left({ }^{14} \mathrm{C}\right.$ )-choline (OM-G-PC) and centrifuged off after 24, 28 and $72 \mathrm{~h}$. After extracting the sediment with chloroform/methanol, the lipid extract was spread onto silica gel plates and developed with the developing solvent mixture of chloroform/methanol/ glacial acetic acid and water $100: 60: 20: 5$ (by volume). Increasing amounts of 1,2-(diacyl)-sn-glycero-3-phospho- $\left({ }^{14} \mathrm{C}\right)$-choline (1,2-diacyl-sn-G-PC*) form in a time-dependent manner by direct transfer of the phosphocholine residue to diacylglycerol. 

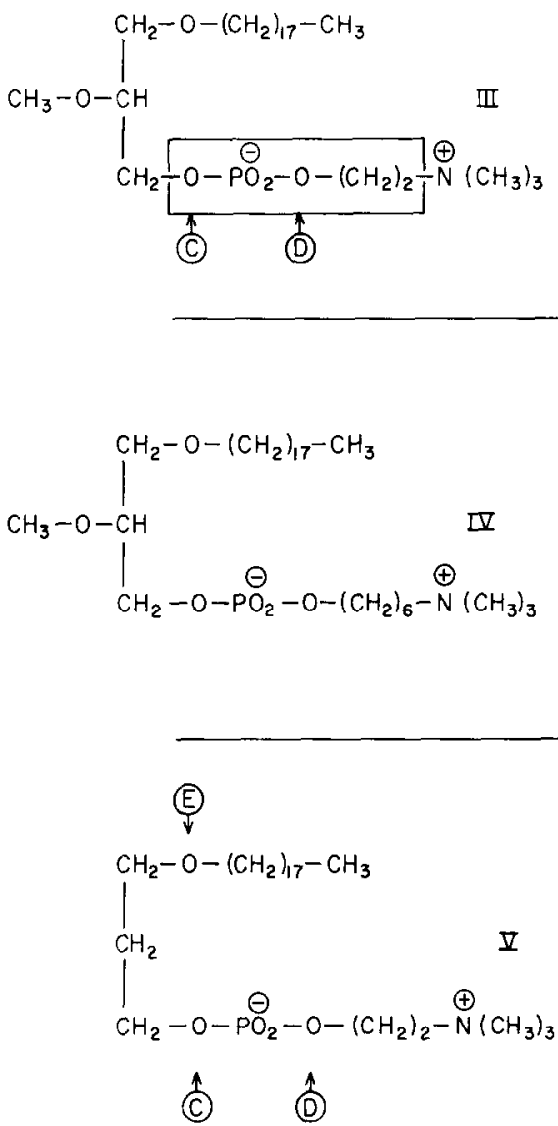

Figure 6. Chemical structure of (ether)-lysolecithins. The arrows indicate attack sites for phospholipid metabolizing enzymes: $\mathrm{C}$, phospholipase $\mathrm{C} ; \mathrm{D}$, phospholipase $\mathrm{D} ; \mathrm{E}, \boldsymbol{O}$-alkylglycerol monooxygenase. The squaredin area contains structural elements which are essential for antineoplastic activity.

\section{Hexadecylphosphocholine: a new and selective antitumor drug}

Structural parameters that influence the antitumor activity of (ether)-lysolecithins suggest that the glycerol moiety is more of a disadvantage. This moiety mediates substrate properties towards phospholipid-metabolizing enzymes such as acyltransferases, transesterases, phospholipases and alkylglycerol monooxygenases, enzymes which must be inhibited in order to achieve antineoplastic activity. Consequently, glycerol as a characteristic structural element of phospholipid molecules can be eliminated. From our experience, the minimal structural elements for antineoplastic activity are alcohols with 16 or 18 carbon atoms which are esterified with a phosphocholine residue; this creates a whole new class of substances with antineoplastic activity: the alkylphosphocholines. We deal herc only with one important representative of the alkylphosphocholines: hexadecylphosphocholine.

Figure 7 compares 1-O-octadecyl-2-O-methyl-rac-glycero-3-phosphocholine, hexadecylphosphocholine and hexadecylphospho- $(N, N, N$-trimethyl $)$ butanolamine. As shown for similar compounds, all three substances have comparable physical properties with regard to their bchavior in monomolccular films (4), in critical micelle concentration (12) or in the critical concentration for hemolysis of erythrocytes $(1,16)$. Similar to 1-O- 


$$
\begin{aligned}
& \mathrm{CH}_{3}-\left(\mathrm{CH}_{2}\right)_{17}-\mathrm{O}-\mathrm{CH}_{2} \\
& \mathrm{CH}_{3}-\mathrm{O}-\mathrm{CH}
\end{aligned}
$$

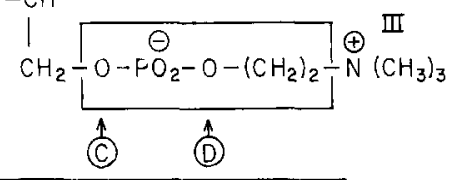

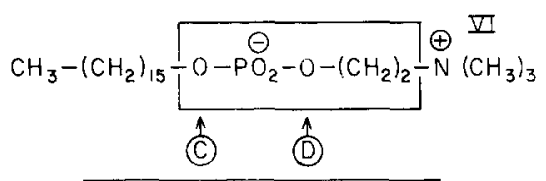

$$
\begin{aligned}
& \mathrm{CH}_{3}-\left(\mathrm{CH}_{2}\right)_{15}-\stackrel{\ominus}{\ominus}-\mathrm{PO}_{2}-\mathrm{O}-\left(\mathrm{CH}_{2}\right)_{4}-\stackrel{\oplus}{\stackrel{\mathrm{V}}{\mathrm{N}}\left(\mathrm{CH}_{3}\right)_{3}}
\end{aligned}
$$

Figure 7. Chemical structure of hexadecylphosphocholine and an analog with extended distance between phosphate and trimethylammonia. The arrow indicates sites of attack for phospholipid metabolizing enzymes: C, phospholipase $\mathrm{C}$; D, phospholipase D. The squared-in area comprises structural elements which are essential for antineoplastic activity.
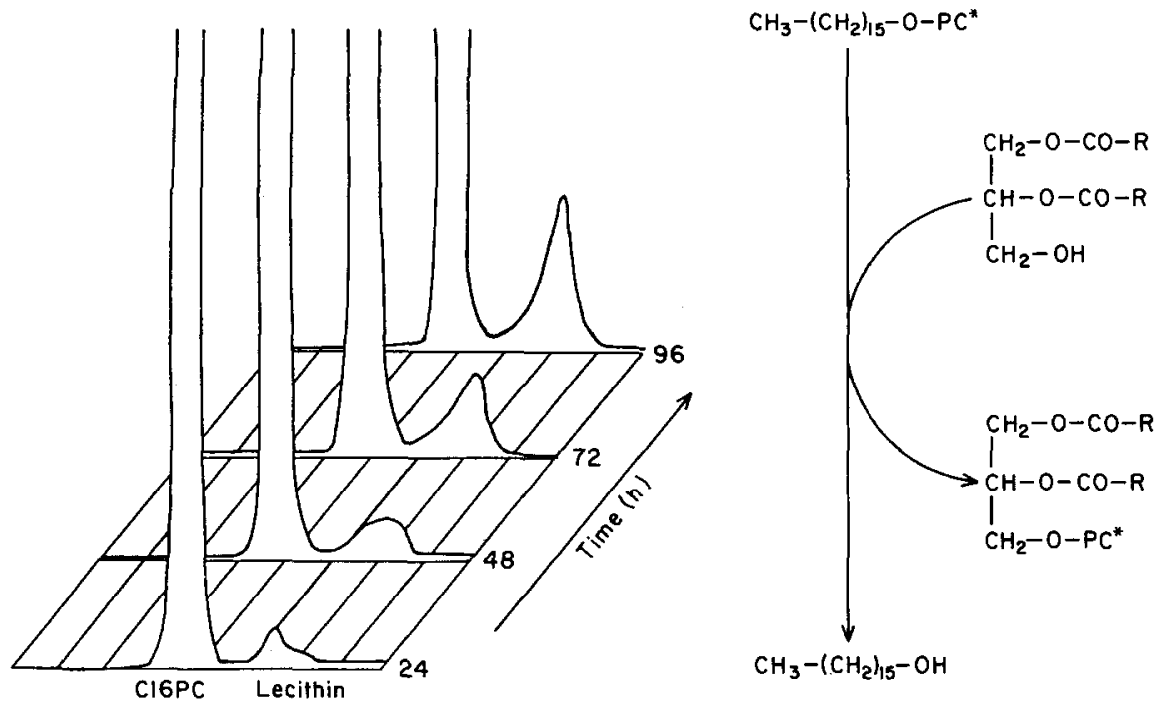

Figure 8. Metabolism of hexadecylphosphocholine in Raji cell cultures. The cells were incubated with labelled hexadecylphospho- $\left({ }^{14} \mathrm{C}\right)$-choline and prepared as described in Figure 5 . Instead of the acidic system, a developing solvent system of chloroform/methanol $/ 25 \%$ ammonia $50: 50: 5$ (by volume) was used. Increasing amounts of 1,2-(diacyl)-lecithin were formed in a time-dependent manner which occurred through a direct transfer of the phosphocholine group to diacylglycerol (see schematic representation).

octadecyl-2-O-methyl-rac-glycero-3-phosphocholine, hexadecylphosphocholine is a marginal substrate for phospholipase $\mathrm{C}$ and $\mathrm{D}$ (Figure 8 ) and also antineoplastically effective. On the other hand, hexadecylphospho-( $N, N, N$-trimethyl)-butanolamine is lacking the substrate properties for the necessary phospholipases mentioned. In animal experiments, it has been ineffective against chemically induced, autochthonous mammary carcinomas. 


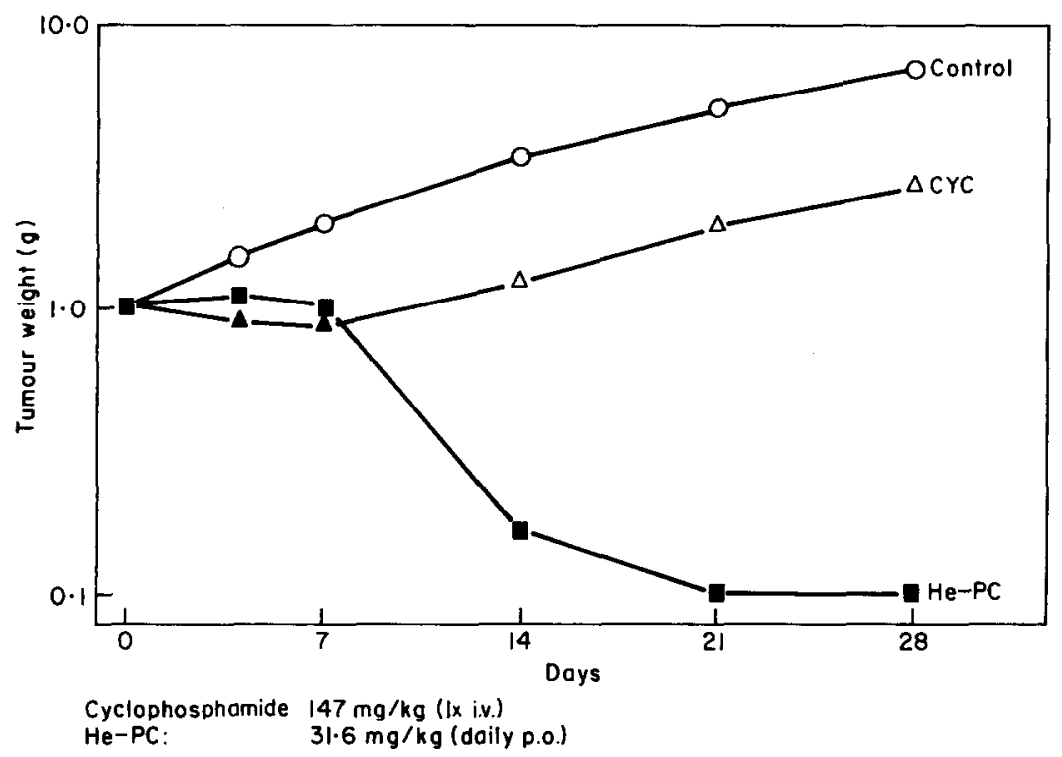

Figure 9. Comparison of the antineoplastic activity of hexadecylphosphocholine and cyclophosphamide on dimethylbenzanthracene-induced mammary carcinoma of the rat: $\mathrm{O}$, controls; $\mathbf{X}$, cyclophosphamide (single intravenous application of the maximally tolerable dose of $147 \mathrm{mg} / \mathrm{kg}$ ); hexadecylphosphocholine (oral administration via a stomach tube: $31.6 \mathrm{mg} / \mathrm{kg}$ daily). Cyclophosphamide had a short-term tumorostatic effect. Administration of hexadecylphosphocholine led to complete remission within a period of 20 days without measurable side effects.

This demonstrates that phosphocholine is a necessary prerequisite of antineoplastic activity in alkylphosphocholines.

Surprisingly, in the chemically induced mammary carcinoma models mentioned, hexadecylphosphocholine is superior to 1-O-octadecyl-2-O-methyl-rac-glycero-3-phosphocholine. For the first time, complete remissions were achieved in these difficult to treat models $(9,14)$. These recent experiments prove the tumoricidal activity of hexadecylphosphocholine, whcrcas only a tumorostatic activity could bc shown for 1-Ooctadecyl-2-O-methyl-rac-glycero-3-phosphocholine. The lack of bone marrow toxicity is useful for the long-term administration of this drug. The activity of hexadecylphosphocholine is exemplified by its effect on the dimethylbenzanthracene-induced mammary carcinoma model. Figure 9 illustrates the activity of orally administered hexadecylphosphocholine versus a single, maximally tolerated intravenous injection of cyclophosphamide in tumor bearing rats. Cyclophosphamide shows a slight reduction in tumor weight after a period of 7 days compared to the controls. Hexadecylphosphocholine, on the other hand, causes complete remission after 20 days. The effect of hexadecylphosphocholine is also independent of the size of the original tumor. In all experiments to date, we have achieved complete remissions, independent of the original tunor size.

\section{First clinical experience}

The positive results of the first animal expcriments on chemically induced rat mammary carcinoma led us to initiate clinical trials with hexadecylphosphocholine. Two forms of 
administration were chosen for clinical use: oral and topical. Topical application was used for treating skin metastases of cutaneous metastatic breast cancer. The oral route was chosen to test the tolerability and efficacy of the substance on solid, metastatic tumors within the framework of a Phase I study.

For topical application, hexadecylphosphocholine was taken up into a mixture of 1-O. alkylglycerols of the alkyl chain lengths $\mathrm{C}_{3}$ (1-O-proplyglycerol), $\mathrm{C}_{6}$ (1-O-hexylglycerol), $\mathrm{C}_{9}$ (1-O-nonylglycerol) and water in such a way that the solution remained single-phase. 1-O-alkylglycerols are membrane permeable amphilic molecules. This property allows them to change the permeability of membranes and also improves the penetration of cytostatics across the blood brain barrier (19).

To date, 25 patients have been treated with this mixture of alkylglycerols and hexadecylphosphocholine. All patients previously have had intensive therapy (chemo-, radioor hormone therapy). The results of this treatment on the 22 evaluable patients are as follows: four had a complete remission, two had a partial remission and six were stable over a maximum period of 12 months. In the other 10 patients the treatment was apparently unsuccessful and their tumors progressed.

The good local tolerability of the mixture was impressive. Cutaneous side-effects were mild: moderate dryness of the skin, epithelial scaling and in isolated cases, itching. In several cases, skin biopsies were taken which histologically showed normal skin architecture after treatment over several months. It should be stressed that no hematological toxicity or other changes in blood chemistry were observed. A multicenter Phase II study on the topical therapy of skin metastases is currently ongoing. In addition, we initiated a clinical Phase I study for oral application of hexadecylphosphocholine.

\section{Summary}

Interdisciplinary cooperation between basic and clinical research has resulted in the discovery and development of alkylphosphocholines, a new class of substances for the treatment of breast cancer. In contrast to most antitumor substances, the alkylphosphocholines do not attack the cell nucleus, but the cell membrane. This report presents a systematic study which, for the first time, provides a correlation between their chemical structure, antitumor efficacy and selectivity. Through an understanding of the metabolism of tumor growth inhibiting (ether)-lysolecithins, the minimal structural requirements for the antineoplastic efficacy of these substances have been obtained. This knowledge was used to identify molecular structures which are more effective and less toxic for the organism.

The active principle derived from a study of (ether)-lysolecithins active as antitumor agents represents a new class of compounds: the alkylphosphocholines. As reported here, hexadecylphosphocholine is the most promising candidate of this group of compounds. It has an extremely selective action against chemically induced, autochthonous rat mammary carcinomas. No loss of activity was observed when comparing oral and intravenous administration. Particularly striking (and favorable for long-term therapy) is the fact that immunosuppression and hematotoxicity were not found at drug concentrations which lead to complete tumor remissions. Results obtained from animal experiments have been confirmed by preliminary clinical investigations. 


\section{References}

1. Arnold, D. \& Weltzien, H. U. (1968) Uber die strukturabhänginge hämolytische Aktivität einiger CholinPhosphatide. Z. Naturforsch. 23b: 675-683.

2. Berdel, W. E. (1986) Experimentelle Ergebnisse und erste klinische Erfahrungen mit Alkyl-Lysophospholipid-Derivaten und anderen Anther-Lipid-Derivaten. Stuttgart-New York: Georg Thieme Verlag.

3. Berger, M. R., Muschiol, C., Schmähl, D., Unger, C. \& Eibl, H. (1985) Chemotherapeutische Studien zur Struktur-Wirkungs-Bezlehung zytotoxischer Alkyllysophospholipide an chemisch Induzierten Mammakarzinomen der Ratte. In: Unger, C., Eibl, H. \& Nagel, G., eds., Die Zellmembran als Angriffspunkt in der Tumortherapie; Aktuelle Onkologie 34, pp. 27-36. München-Bern-Wien: Zuckschwerdt Verlag.

4. Eibl, H., Demel, R. A. \& van Deenen, L. L. M. (1969) Monolayers of lysolecithins and analogs. $J$. Coll. Inferf. Sci. 29: 381-387.

5. Eibl, H., Hill, E. E. \& Lands, W. E. M. (1969) The subcellular distribution of acyltransferases which catalyse the synthesis of phospholipids. Eur. J. Biochem. 9: 250258.

6. Eibl, H. \& Woolley, P. (1988) A general synthesis method for enantiomerically pure ester and ether lysophospholipids. Chem. Phys. Lipids 47: 63-68.

7. Cibl, II. \& Woolley, P. (1986) Synthesis of enantiomerically pure glyceryl esters and ethers: I. Methods employing the precursor 1,2-isopropylidene-sn-glycerol. Chem. Phys. Lipids 41: 53-63.

8. Eibl, H. \& Woolley, P. (1988) Synthesis of enantiomerically pure glyceryl esters and ethers: II. Methods employing the precursor 1,2-isopropylidene-D-manitol. Chem. Phys. Lipids 47: 47-53.

9. Hilgard, P., Stekar, J., Voegill, R., Engel, J., Schumacher, W., Eibl, H., Unger, G. \& Berger, M. (1988) Characterization of the antitumor activity of hexadecylphosphocholine (D 18506). Eur. J. Cancer Clin. Oncol. 24: $1457-1461$.

10. Kötting, J., Unger, C. \& Eibl, H. (1987) A continuous assay for O-alkylglycerol monooxygenase (E.C. 1.14.16.5). Lipids 22: 824-830.

11. Kötting, J., Unger, C. \& Eibl, H. (1987) Substrate specificity of O-alkylglycerol monooxygenase (E.C. 1.14.16.5), solubilized from rat liver microsomes. Lipids 22: 831-835.

12. Kovatchev, S., Vaz, W. L. C. \& Eibl, H. (1981) Lipid dependence of the membrane-bound D-lactate dehydrogenase of Escherichia coli. Biochemistry F256: 10369-10374.

13. Munder, P. G. (1973) Blochemische und biologische Untersuchungen zum Wirkungsmechanismus von Adjuvantien. Habilitation, University of Freiburg.

14. Muschio, C., Berger, M. R., Schuler, B., Scherf, H. R., Garzon, F. T., Zeller, W. J., Unger, C., Eibl, H \& Schmähl, D. (1987) Alkyl phosphocholines: toxicity and anticancer properties. Lipids 22: 930-934.

15. Neumüller, W., Fleer, E. A. M., Unger, C. \& Eibl, H. (1985) Enzymatic acylation of ether and ether lysophospholipids in rat liver microsomes. Lipids 22: 808-812.

16. Reman, F. C., Demel, R. A., de Gler, J., van Deenen, L. L. M., Eibl, H. \& Westphal, O. (1969) Studies on the lysis of red cells and biomolecular lipid leaflets by synthetic lysolecithine, lecithine structural analogs. Chem. Phys. Lipids 3: 221-233.

17. Soodsma, J. F., Piantadosl, C. \& Synder, F. (1970) The biocleavage of alkylglycerl ethers in Morris hepatomas and other transplantable neoplasms. Cancer Res. 30: 309-311.

18. Unger, C., Eibl, H., Kim, D. J., Fleer, E. A. M., Kötting, J., Bartsch, H. H., Nagel, G. A. \& Pfizenmaier, K. (1987) Sensitivity of leukemia cell lines to cytotoxic alkyl-lysophospholipids in relation to $\mathrm{O}$-alkyl cleavage enzyme activities. J. Natl. Cancer Inst. 78: 219-222.

19. Unger, C., Eibl, H., von Heyden, H. W., Krisch, B. \& Nagel, G. A. (1985) Blut-Hirnschranke und Penetration von Zytostatika. Klin. Wochenschr, 63: 565-571.

20. Unger, C., Eibl, H., von Heyden, H. W. \& Nagel, G. A. (1985) New assay for the O-alkyl cleavage enzyme with alkyl-lysophospholipids as substrates. Cancer Res. 45: 616-618.

21. Wolley, P. \& Eibl, H. (1988) Synthesis of enantiomerically pure phospholipids including phosphatidylserine and phosphatidylglycerol. Chem. Phys. Lipids 47: 55-62. 